\title{
PERENCANAAN ARTIFICIAL REEF SEBAGAI RESTORASI TERUMBU KARANG DAN PENGAMAN PANTAI DI PULAU LEMUKUTAN KABUPATEN BENGKAYANG
}

\author{
Dhiecho Mahar Dhiecha, Kiki Prio Utomo, Dian Rahayu Jati \\ Program Studi Teknik Lingkungan, Fakultas Teknik, Universitas Tanjungpura, Pontianak \\ Email : dhiecho.env.08@engineer.com
}

\begin{abstract}
ABSTRAK
Kerusakan yang terjadi disekitar kawasan Pulau Lemukutan disebabkan penggunaan bahan kimia atau potas untuk menangkap ikan hias dan terumbu karang oleh masyarakat setempat, selain itu penggunaan bom juga sering dilakukan masyarakat sekitar untuk mengambil karang-karang indah yang akan dijual sehingga merusak ekosistem terumbu karang di perairan tersebut. Metode perencanaan terumbu karang buatan (Artificial reef) sebagai restorasi terumbu karang dan pengaman pantai adalah dengan melakukan survei lapangan topografi menggunakan alat ukur GPS, data kualitas air laut dan menggunakan data sekunder yaitu data statistik, pasang surut, tinggi gelombang, peta bathimetri, arah arus dan arah angin. Analisa kualitas air dilakukan secara in-situ, parameter yang di uji adalah kecerahan perairan, arus, salinitas, suhu, pH. Analisis terumbu buatan yang berfungsi semagai restorasi terumbu karang dan sebagai pengaman pantai yaitu menggunakan tipe kubah berongga atau reef balls. Lokasi penempatan yang sesuai dan berada pada koordinat $\mathrm{N} 0^{\circ} 45^{\prime} 33.8^{\prime \prime}$, E $108^{\circ} 42^{\prime} 19.5^{\prime \prime}$ sampai $\mathrm{N} 0^{\circ} 45^{\prime} 29.2^{\prime \prime} \mathrm{E} 107^{\circ} 15^{\prime} 49.0^{\prime \prime}$ dan pada kedalaman rata-rata 3 meter. Hasil pengujian kualitas air berdasarkan parameter salinitas, kecepatan arus, $\mathrm{pH}$, kekeruhan, intensitas cahaya dan suhu memenuhi syarat baku mutu kehidupan karang di Indonesia berdasarkan pada PERMEN LH No 51 Tahun 2004. Dimensi terumbu karang buatan berdiameter $1,80 \mathrm{~m}$, tinggi $1,50 \mathrm{~m}$ dengan tebal lapisan $10 \mathrm{~cm}$ serta lubang yang berada pada sisi-sisi terumbu buatan sebanyak 34 lubang dengan diameter $15 \mathrm{~cm}$. Bahan pengisi yang digunakan adalah beton dengan volume 0,916 $\mathrm{m}^{3}$ atau setara dengan 2,198 ton. Bahan pengikat atau semen yang digunak yaitu tipe $V$ yang tahan terhadap kadar sulfat yang tinggi. Jumlah reef balls yang digunakan addalah sebanyak 834 buah.

Kata kunci: Artificial reef, Kualitas Air Laut, Reef balls dan Terumbu karang,.
\end{abstract}

\section{ABSTRACT}

Damage that occurs around the area Lemukutan Island caused the use of chemicals or cyanide to catch fish and coral reefs by local people, but it is also often made use of bombs surrounding communities to take beautiful corals that will be sold to destroy coral reef ecosystems in the waters. Artificial reef planning methods (Artificial reef) as the restoration of coral reefs and coastal protection is to conduct a field survey using a measuring instrument GPS topographic, marine water quality data and using secondary data, statistical data, tidal, wave height, bathymetry map, direction of flow and wind direction. Water quality analysis carried out in-situ, parameter test in the brightness of the water, currents, salinity, temperature, $\mathrm{pH}$. Analysis of the function of Artificial reefs for reef restoration and as coastal protection is to use a hollow dome type or reef balls. Appropriate placement location and located at coordinates $N 0^{\circ} 45$ '33.8 ", E $108^{\circ} 42^{\prime} 19.5^{\prime \prime}$ up to $N O^{\circ} 45^{\prime} 29.2^{\prime \prime} E 107^{\circ} 15^{\prime} 49.0^{\prime \prime}$, and the average depth of 3 meters. Results of water quality testing based on parameters salinity, current velocity, $p H$, turbidity, light intensity and temperature qualify coral life quality standards in Indonesia based on PERMEN LH No. 51 TAHUN 2004. The dimensions of Artificial reef $s$ diameter of $1.80 \mathrm{~m}$, height $1.50 \mathrm{~m}$ with a thick layer of $10 \mathrm{~cm}$ and a hole located on the sides of the Artificial reef for 34 holes with a diameter of $15 \mathrm{~cm}$. Filler material used is concrete with a volume of $0.916 \mathrm{m3}$, equivalent to 2,198 tons. Binder or cement used type $V$, which is resistant to high sulfate levels. The amount of reef balls used is 834 pieces.

Keywords: Artificial reef, Seawater Quality, Reef balls and coral reefs, 


\section{Pendahuluan}

Kabupaten Bengkayang, Provinsi Kalimantan Barat, merupakan hasil pemekaran dari Kabupaten Sambas. Wilayah pesisir Bengkayang terletak di Kecamatan Sungai Raya, memiliki ekosistem yang menarik dan berpotensi untuk dikembangkan sebagai wisata bahari. Dengan keistimewaan yang dimiliki kawasan ini khususnya di Pulau Lemukutan, Pemerintah Kabupaten Bengkayang telah menetapkan Pulau Lemukutan sebagai Kawasan Konservasi dan Wisata Alam Laut Bengkayang sesuai Surat Keputusan Bupati Bengkayang No. 220 Tahun 2004, Tanggal 16 Desember 2004 (Departemen Kelautan dan Perikanan, 2004).

Seiring dengan meningkatnya berbagai akitivitas pemanfaatan sumberdaya pesisir dan laut di kawasan Pulau Lemukutan dan sekitarnya, sebagai konsekuensi dari pertambahan penduduk di wilayah tersebut, telah menimbulkan berbagai tekanan terhadap kondisi terumbu karang di kawasan tersebut. Hasil survey kondisi terumbu karang pada tahun 2005 di Lemukutan dan sekitarnya, menunjukan bahwa secara umum kondisinya sedang hingga bagus dengan luas penutupan karang hidup sebesar $50-74,9 \%$ ( Departemen Kelautan dan Perikanan, 2004).

Berdasarkan studi kasus yang terjadi di Pulau Lemukutan, menjadi sangat penting artinya kegiatan perencanaan Artificial reef sebagai restorasi terumbu karang untuk mengganti dan memperbaiki keadaan terumbu karang di Pulau Lemukutan yang memiliki potensi keanekaragaman jenis biota laut, ekosistem dan sangat berpotensi sebagai tempat pariwisata. Terumbu karang buatan atau Artificial reef juga dapat memiliki peranan sebagai pelindung pantai dari pengikisan gelombang air laut atau abrasi.

\section{Gambaran Umum Lokasi Studi}

Secara geografis, Kecamatan Sungai Raya Kepulauan terletak pada $0^{0} 38^{\prime} 39^{\prime \prime}$ Lintang Utara sampai dengan $0^{\circ} 51^{\prime} 21^{\prime \prime}$ Lintang Utara dan $108^{\circ} 18^{\prime} 14^{\prime \prime}$ Bujur Timur sampai dengan $108^{\circ} 59^{\prime} 02^{\prime \prime}$ Bujur Timur. Luas wilayah Kecamatan Sungai Raya Kepulauan adalah sebesar $394,00 \mathrm{~km}^{2}$ atau sekitar 7,30 persen dari seluruh luas Kabupaten Bengkayang. Kecamatan Sungai Raya Kepulauan terbagi dalam lima desa. Kecamatan Sungai Raya Kepulauan terbentuk pada tahun 2006. Dilihat luas per desa, luas wilayah desa yang paling besar adalah Desa Karimunting dengan luas wilayah sebesar $194,50 \mathrm{~km}^{2}$ atau sekitar 49,37 persen dari total luas Kecamatan Sungai Raya Kepulauan sedangkan luas desa yang paling kecil adalah Desa Sungai Keran dengan luas wilayah hanya $15,30 \mathrm{~km}^{2}$ atau sekitar 3,88 persen dari seluruh luas wilayah Kecamatan Sungai Raya Kepulauan.

Pesisir laut Kabupaten Bengkayang berbatasan dengan Laut Cina Selatan atau Laut Natuna. Kabupaten Bengkayang memiliki pulau-pulau kecil diantaranya adalah Pulau Lemukutan, Pulau Randayan, Pulau kabung, Pulau Penata Besar, Penata Kecil, Seluas, Baru, Semesa, Tempurung, Kera, Batu Payung dan Pulau Batu Bukit. (Badan Pusat Statistik, 2012).

\section{Tinjauan Teori}

a. Terumbu Karang

Pada dasarnya terumbu karang terbentuk dari endapan-endapan masif kalsium karbonat $\left(\mathrm{CaCO}^{3}\right)$ yang dihasilkan oleh organisme karang pembentuk terumbu (karang hermartipik) dari filum Cnidaria, ordo Scleractinia yang hidup bersimbiosis dengan zooxantellae, dan sedikit tambahan dari algae berkapur serta organisme lain yang menyekresi kalsium karbonat (Bengen, 2002).

Hewan karang termasuk kelas Anthozoa, yang berarti hewan berbentuk bunga (Antho artinya bunga; zoa artinya hewan). Lebih lanjut dikatakan bahwa Aristoteles 
mengklasifikasikan hewan karang sebagai hewan-tumbuhan (animal plant). Baru pada tahun 1723, hewan karang diklasifikasikan sebagai binatang.

b. Fungsi dan Manfaat Terumbu Karang

Manfaat yang terkandung di dalam ekosistem terumbu karang sangat besar dan beragam, baik manfaat langsung dan manfaat tidak langsung. Manfaat langsung antara lain sebagai habitat ikan dan biota lainnya, pariwisata bahari, dan lain-lain. Sedangkan manfaat tidak langsung, antara lain sebagai penahan abrasi pantai dan pemecah gelombang. Terumbu karang adalah salah satu ekosistem laut yang paling penting sebagai sumber makanan, habitat berbagai jenis biota komersial, menyokong industri pariwisata, menyediakan pasir untuk pantai, dan sebagai penghalang terjangan ombak dan erosi pantai (Westmacott et al, 2000).

c. Parameter yang Mempengaruhi Keberadaan Terumbu Karang

Pertumbuhan karang dan penyebarannya tergantung pada kondisi lingkungannya, yang pada kenyataannya tidak selalu tetap karena adanya gangguan yang berasal dari alam atau aktivitas menusia. Menurut Dahuri (1996) terumbu karang terdapat pada lingkungan perairan yang agak dangkal. Untuk mencapai pertumbuhan yang maksimum, terumbu karang memerlukan perairan yang jernih, dengan suhu perairan yang hangat, gerakkan gelombang besar dan sirkulasi air yang lancar serta terhindar proses sedimentasi. Baku mutu perairan sesuai peruntukannya yang berlaku di Indonesia dapat dilihat pada tabel 1 berikut (KEPMEN LH No. 51 Tahun 2004).

Tabel 1. Nilai parameter kualitas air untuk kehidupan karang

\begin{tabular}{|l|l|l|}
\hline \multicolumn{1}{|c|}{ Parameter } & \multicolumn{1}{c|}{ Satuan } & \multicolumn{1}{c|}{ Baku mutu untuk kehidupan karang } \\
\hline Kejernihan Air & $\mathrm{m}$ (meter) & $>5 \mathrm{~m}$ \\
\hline Sedimen Load & - & $\begin{array}{l}\text { Sedimentasi dari arah daratan harus minmal/ } \\
\text { kecepatan sedimentasi rendah }\end{array}$ \\
\hline Fosfor & $\mathrm{Ppm}$ & $0,015 \mathrm{ppm}$ \\
\hline Silikon & $\mathrm{ppm}$ & $0-8,4 \mathrm{ppm}$ \\
\hline Kecepatan arus & $\mathrm{m} / \mathrm{s}$ & $<0,9 \mathrm{~m} / \mathrm{s}$ \\
\hline Suhu & ${ }^{0} \mathrm{C}$ & $28-30{ }^{\circ} \mathrm{C}$ \\
\hline Salinitas & $\mathrm{ppt}$ & $30-35 \mathrm{ppt}$ \\
\hline
\end{tabular}

d. Faktor-faktor Penyebab Rusaknya Terumbu Karang

Menurut Burke et al. (2002) bahwa Terdapat beberapa penyebab kerusakan terumbu karang yaitu :

1. Pembangunan di wilayah pesisir yang tidak dikelola dengan baik

2. Aktivitas di laut antara lain dari kapal dan pelabuhan termasuk akibat langsung dari pelemparan jangkar kapal

3. Penebangan hutan dan perubahan tata guna lahan yang menyebabkan peningkatan sedimentasi

4. Penangkapan ikan secara berlebihan memberikan dampak terhadap keseimbangan yang harmonis di dalam ekosistem terumbu karang

5. Penangkapan ikan dengan menggunakan racun dan bom

6. Perubahan iklim global. 
e. Terumbu Karang Buatan (Artificial reef)

Terumbu karang buatan (Artificial reefs) adalah habitat buatan yang di bangun di laut dan diletakkan didasar perairan yang tidak produktif dengan meniru beberapa karakteristik terumbu alami dengan maksud memperbaiki ekosistem yang rusak, sehingga dapat memikat jenis-jenis organisme laut untuk hidup dan menetap serta meningkatkan produksi perikanan, biasanya terbuat dari timbunan bahan-bahan yang sifatnya berbeda satu sama lain seperti ban bekas, cetakan semen atau beton, bangkai kerangka kapal, ban mobil bekas, bambu dan sebagainya (Dirjen KP3K et al, 2005).

- Bentuk Terumbu Karang Buatan

Pemilihan terumbu buatan sebagai struktur dalam perlindungan garis pantai adalah untuk mempertahan kan estetika keindahan panorama pantai yang alamiah, sehingga tidak terganggu dengan adanya struktur pelindung pantai. Terumbu buatan (Artificial reef) jenis ini berfungsi untuk menjadi tempat tinggal atau sarang baru bagi ikan dan dapat melestarikan ekologis terumbu karang sebagai habitat biota laut seperti ikan dan lain sebagainya serta dapat mereduksi gelombang sehingga dapat menjadi sebagai pengaman pantai. Pada Gambar 1 dapat dilihat bentuk dan jenis terumbu karang buatan.

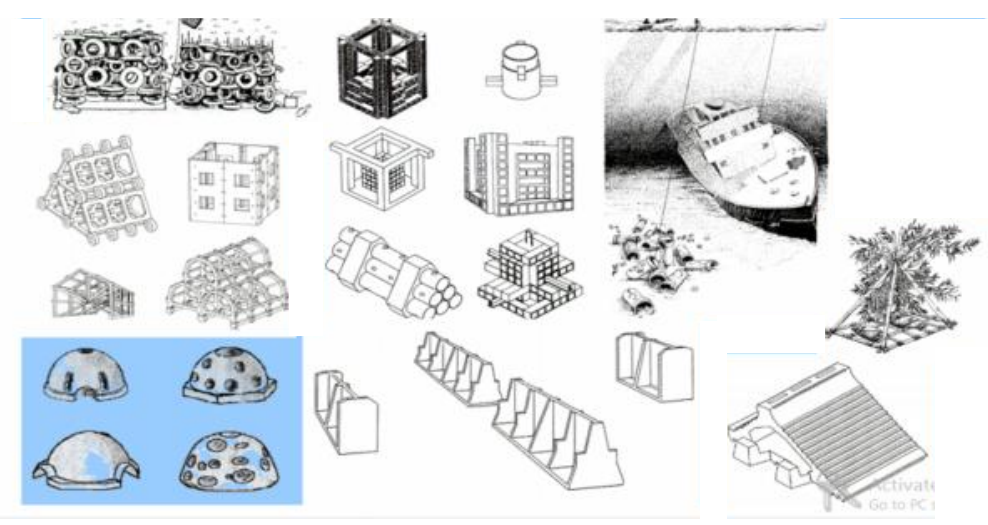

Gambar 1. Jenis-jenis terumbu karang buatan (Artificial reef)

- Bahan dan Konstruksi Terumbu Karang Buatan

Berbagai jenis bahan yang digunakan untuk pembuatan konstruksi terumbu buatan Terumbu buatan bisa dibuat dari beton biasanya menggunakan Semen Portland tipe $\mathrm{V}$ yang dalam penggunaannya memerlukan ketahanan tinggi terhadap sulfat. Semen jenis ini cocok digunakan untuk pembuatan beton pada daerah yang tanah dan airnya mempunyai kandungan garam sulfat tinggi seperti : air laut, daerah tambang, air payau dsb. (Murdock, L. J. dan Brook, K. M., 1999)

f. Perhitungan Terumbu Buatan Bentuk Kubah Beton Berongga (Reef balls) Jaringan peneliti terumbu karang buatan di Eropa (European Artifcial Reef Research Network - EARNN) mendefinisikan terumbu karang buatan (Artificial reef ) sebagai suatu bangunan yang sengaja dibenamkan untuk menirukan karakteristik terumbu karang (coral reef). Istilah terumbu karang buatan untuk berbagai benda buatan juga didefinisikan sebagai suatu struktur buatan manusia yang berfungsi sebagai tempat berlindung dan habitat, sumber makanan dan tempat pemijahan bagi hewan-hewan laut (Harris, 2001). 


\section{g. Penentuan Lokasi}

Terumbu buatan ditempatkan pada habitat yang mengalami penurunan dan area yang memiliki produktifitas yang rendah (Yahmantoro dan Budiyanto 1991). Beberapa kriteria dalam meletakkan terumbu buatan:

1. Lokasi dekat dengan pemukiman nelayan.

2. Terpisah dari terumbu alami.

3. Perairan cukup jernih.

4. Kedalaman berdasarkan jarak dari pesisir perairan dan kemampuan penyelam melakukan pengamatan pada kedalam yang bersangkutan.

5. Kondisi perairan memenuhi syarat hidup terumbu karang (Sirkulasi, saliitas, kecerahan, sedimentasi dan kedalaman).

6. Lokasi jauh dari area penangkapan ikan terutama Trawl.

7. Keadaan substrat sukup keras dan berbentuk flat (rata) untuk mencegah terumbu buatan tertanam ke dasar.

8. Orientasi (letak) dalam hubungan dengan pola migrasi ikan dan.

9. Tidak membahayakan navigasi.

\section{Metodologi Perencanaan.}

Jenis data yang dikumpulkan pada perencanaan ini adalah data primer dan data sekunder. Data primer didapat dari hasil pengukuran lapangan, terdiri dari survei topografi bathimetri (elevasi dan jarak), Data kualitas air laut (salinitas, kecepatan arus laut, pH,suhu, kekeruhan). Data sekuder yaitu data hidrologi, data klimatologi (data arah angin, pasang surut air laut stasiun Pemangkat, dan data arah arus pada tahun 2013), Peta-peta, yaitu peta bathimetri, peta administrasi peta arah arus dan wind roses. Menganalisis bentuk konstruksi atau dimensi terumbu buatan, bahan dan metode yang sesuai dengan lokasi perencanaan. Merencanakan dan menentukan ukuran terumbu karang buatan serta gambar detail desain. Gambar detail desain akan digunakan sebagai pedoman teknis dalam pelaksanaan pekerjaan.

\section{Hasil dan Analisa Perencanaan}

a. Lokasi Penempatan Terumbu Karang Buatan Reef balls

Lokasi penempatan terumbu karang buatan Reef balls berada pada koordinat N $0^{0} 45^{\prime} 33.8^{\prime \prime}$, E $108^{\circ} 42^{\prime} 19.5^{\prime \prime}$ sampai N $0^{\circ} 45^{\prime} 29.2^{\prime \prime}$ E $107^{\circ} 15^{\prime} 49.0^{\prime \prime}$ dapat dilihat pada Gambar 2 Penentuan lokasi reef balls dibagi menjadi tiga bagian dengan panjang terumbu karang buatan setiap bagian adalah 100 meter.

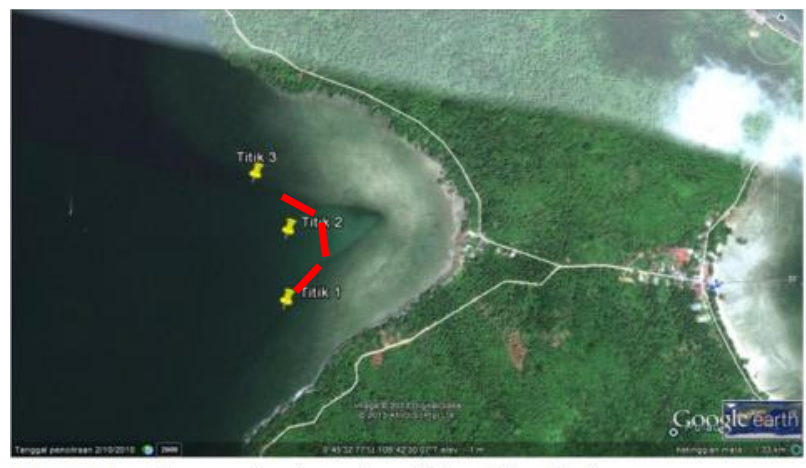

: Terumbu buatan (Reef balls)

Gambar 2. Lokasi penempatan terumbu buatan (Reef balls)

b. Kualitas Air Laut

Pengambilan sampel dilakukan pada tanggal 6 juli 2013, lokasi pengambilan sampel air dapat dilihat pada Gambar 2 dan hasil hasil pengukuran kualitas air 
berdasarkan baku mutu air laut (KEPMEN/LH/2004) dapat dilihat pada tabel 2 .

Tabel 2. Nilai parameter baku mutu air laut dan kualitas air di lokasi perencanan

\begin{tabular}{|l|l|c|c|c|c|}
\hline \multicolumn{1}{|c|}{ Parameter } & Satuan & \multicolumn{2}{c|}{ Hasil yang diuji pada lokasi studi } & Baku mutu untuk kehidupan karang \\
\hline FISIKA & & Titik 1 & Titik 2 & Titik 3 & $>6$ \\
\hline Kecerahan & M & 5 & 6 & 6 & 5 \\
\hline Kekeruhan & NTU & 1,67 & 4,79 & 2,73 & $28-30$ \\
\hline Suhu & ${ }^{0} \mathrm{C}$ & 29 & 30 & 30 & $<0,9$ \\
\hline Kecepatan Arus & $\mathrm{m} / \mathrm{s}$ & 0,24 & 0,3 & 0,24 & $7-9$ \\
\hline Ph & - & 7 & 9 & 9 & $30-35$ \\
\hline Salinitas & $\%$ & 30 & 31 & 31 & \\
\hline
\end{tabular}

Berdasarkan uji sampling yang dilakukan dan membandingkan dari baku mutu kualitas air laut untuk tumbuhnya terumbu karang KEPMEN LH No. 51 dengan parameter salinitas, kekeruhan, kecepatan arus, intensitas cahaya, $\mathrm{pH}$ dan suhu. perairan yang menjadi lokasi penempatan terumbu karang buatan Reef balls sudah memenuhi syarat baku mutu kehidupan terumbu karang.

c. Gelombang dan Pasang Surut

Berdasarkan penelitian yang telah dilakukan pada tahun 2011 dapat dilihat pada Gambar 3 tinggi gelombang pada perairan Kabupaten Bengkayang digambarkan dengan garis $\mathrm{Hs}$. Tinggi gelombang untuk penempatan pada kedalaman 3 meter sesuai tinggi muka air laut maksimum dengan Reef balls dapat dilihat pada garis pada sumbu $x$ yaitu senilai 3 meter dan didapat tinggi gelombang pada sumbu $y$ senilai 1,85 meter.
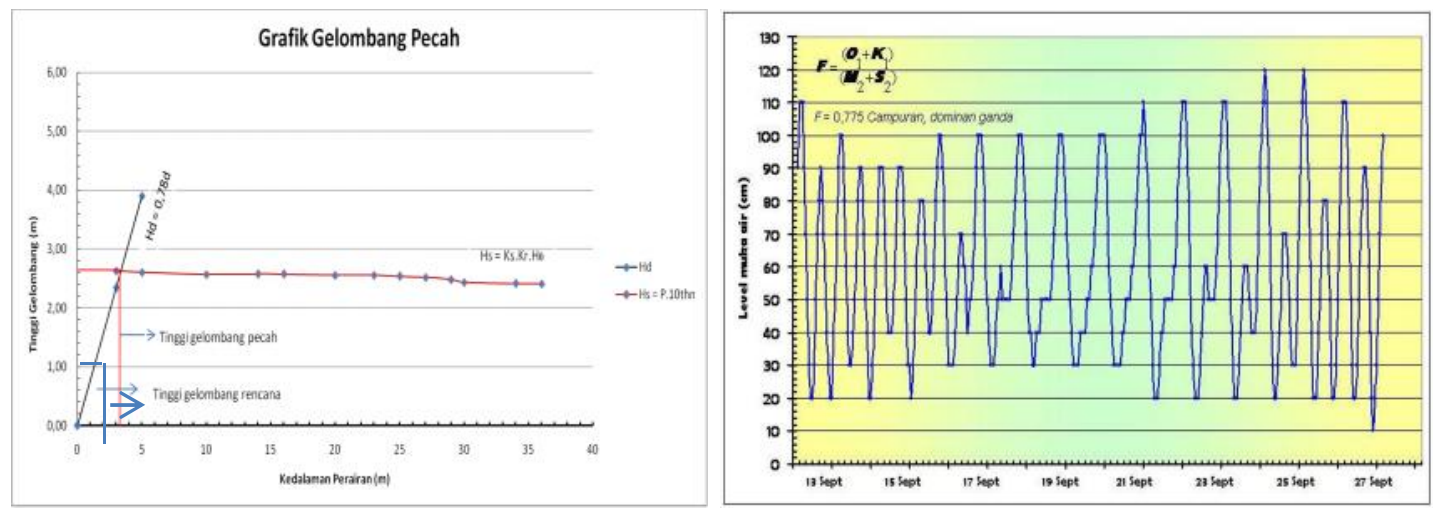

Gambar 3. Grafik gelombang pecah dan Pasang Surut Kabupaten Bengkayang

Data pasang surut hasil dari pengukuran selama 15 hari pada bulan September Tahun 2011 berturut-turut dengan interval waktu 1 jam, dan hasilnya diketahui tinggi air maksimum yaitu pada nilai $120 \mathrm{~cm}$, dan tinggi muka air surut minimum yaitu $10 \mathrm{~cm}$, sedangkan muka air rata-rata yaitu pada ketinggian $55 \mathrm{~cm}$. Grafik pasang surut pada lokasi perencanan dapat dilihat pada Gambar 3.

d. Rancangan Terumbu Karang Buatan

Berdasarkan penelitian yang telah dilakukan bentuk terumbu reef balls memang paling baik karena presentase tutupan dan pertumbuhan karangnya paling tinggi. Selain itu, bentuk reef balls mampu menyesuaikan dengan kondisi lingkungan dengan membelokkan arus yang melewatinya, dengan kondisi tersebut flanula karang menempel dan tumbuh dengan baik pada bagian terumbu buatan yang terlindung dari arus laut. Terumbu buatan jenis ini akan ditempatkan pada kedalaman 3-3,7 meter dipasang terendah dan tinggi pasang maksimal. 
1. Perhitungan Dimensi Reef balls

Perhitungan dan desain dimensi untuk terumbu karang buatan yang digunakan berdasarkan gaya-gaya yang bekerja pada satu buah reef balls memiliki lebar atau berdiameter $1,8 \mathrm{~m}$ dan tinggi $1,5 \mathrm{~m}$ dengan tebal lapisan $20 \mathrm{~cm}$ serta lubang yang berada pada sisi-sisi terumbu buatan sebanyak 34 lubang dengan diameter $15 \mathrm{~cm}$ serta memiliki berat yaitu 2,198 Ton. Penentuan diameter reef balls berdasarkan tinggi gelombang pada lokasi perencanaan atau tinggi gelombang berbanding dengan diameter reef balls.

Gambar 4. Desain terumbu karang buatan Reef balls

a. Volume Reef balls

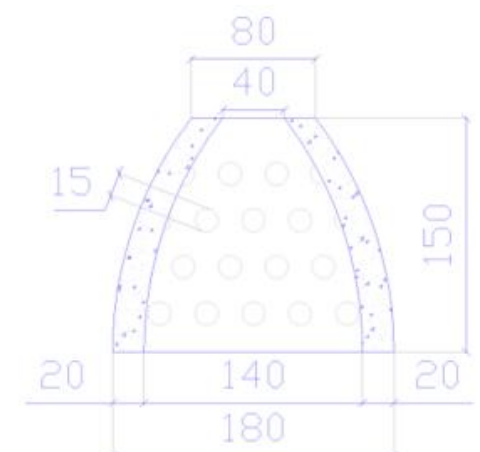

$V=\mid\left(\frac{1}{3} \pi \cdot t\left(R 1^{2}+R 1 r 1+r 1^{2}\right)-\left(\frac{1}{3} \pi \cdot t\left(R 2^{2}+R 2 r 2+r 2^{2}\right) \mid-\sum V_{\text {hole }}\right.\right.$

Dimana,

R1 : 0,9 meter (Jari-jari bawah lingkaran luar)

r1 : 0,4 meter (Jari-jari atas lingkarang luar)

R2 : 0,7 meter (Jari-jari bawah lingkaran dalam)

r2 :0,2 meter (Jari-jari atas lingkarang dalam)

$\mathrm{t} \quad: 1,5$ meter (Tinggi bangunan)

$V_{\text {hole }}=\pi r^{2} \cdot t$

dimana,

$r \quad:$ Jari-jari hole

$\mathrm{t} \quad$ : Tebal hole

Volume Reef Ball:

$V=\|\left(\frac{1}{3} \pi \cdot t\left(R 1^{2}+R 1 r 1+r 1^{2}\right)-\left(\frac{1}{3} \pi \cdot t\left(R 2^{2}+R 2 r 2+r 2^{2}\right) \mid->V_{\text {hole }}\right.\right.$

$V=\|\left(\frac{1}{3} 3,14.1,5\left(0,9^{2}+(0,9 * 0,4)+0,4^{2}\right)-\left(\frac{1}{3} 3.14 .1,5\left(0,7^{2}+(0,7 * 0,2)+0,2^{2}\right) \mid\right.\right.$ $-34\left(3,14 \times 0,075^{2} \times 0,2\right)$

$V=0,916 \mathrm{~m}^{3}=2,198$ Ton

b. Luas Permukaan Reef balls:

$L_{\text {permukaan }}=\pi(R 1+r 1) \cdot S-L_{\text {permukaan Hole }}$

Dimana,

R1 : 0,9 meter (Jari-jari bawah lingkaran luar)

r1 : 0,4 meter (Jari-jari atas lingkarang luar)

$\mathrm{S} \quad: 1,515$ (Kemiringan bangunan)

$L_{\text {Permukaan }}=\pi(R 1+r 1) \cdot S-L_{\text {permukaan Hole }}$

$L_{\text {Permukaan }}=3,14(0,9+0,4) \times 1,515-34\left(3,14.0,15^{2}\right)$

$L_{\text {Permukaan }}=5,108 \mathrm{~m}^{2}$ 
2. Jumlah Reef balls yang Diperlukan

Perletakan reef balls dibagi menjadi tiga bagian tiap bagian memiliki panjang 100 meter. Tiap bagian reef balls memiliki 2 tingkat reff balls, jumlah reff balls tiap bagian adalah 278 buah reef balls. Total reff balls yang digunakan adalah 834 buah reef balls

3. Gaya-gaya Yang Berkerja Pada Reef balls

a. Gelombang (Force Wave)

Gaya oleh gelombang / ombak dapat diperkirakan dengan beberapa cara. Salah satunya dengan cara yang umum dikenal, yaitu cara Morison.

$\mathrm{FT}=\mathrm{CM} \rho \mathrm{A} \mathrm{a}+\mathrm{CD} \rho \mathrm{D}$ u $\mid \mathrm{u}$

$\mathrm{FT}=0,7 * 1,025 * 2,554 * 0,045+0,2 * 1,025 * 0,45$

$\mathrm{FT}=0,2$

b. Gaya Seret (Drag Force)

Maksimum kecepatan partikel horisontal (U) dapat ditentukan dengan persamaan berikut:

$U=\frac{\pi * H}{T} * \frac{\cosh k * z+d}{\sinh k * d} * \cos \emptyset$

$U=\frac{3,14 * 1,35}{7,75} * 1$

$U=0,547$ detik

Mengitung gaya seret dengan persamaan berikut:

Force $_{\text {drag }}=C_{D} \times \rho \times A_{p} \times \frac{U^{2}}{2}$

Force $_{\text {drag }}=0,2 \times 1,025 \times 5,108 \times \frac{0,547^{2}}{2}$

Force $_{\text {drag }}=0,157$ ton

c. Gaya Inersia

Menghitung gaya inersia persamaan Dean, untuk mengetahui besaran gaya inersia terlebih dahulu harus mengetahui percepatan partikel air (a) dan koefisien inersia $\left(C_{M}\right)$, persamaan yang digunakan untuk mengetahui nilai perepatan partikel air (a) sebagai berikut :

$a=\frac{\pi * H g}{L} * \frac{\cosh k * z+d}{\cosh k * d} * \sin \emptyset$

$a=\frac{3,14 * 1,35 * 9,81}{925,065} * 1$

$a=0,045 \mathrm{~m} / \mathrm{s} 2$

Dan untuk nilai koefisien inersia $\left(C_{M}\right)$ dapat menggunakan persamaan sebagai berikut:

$\mathrm{C}_{\mathrm{M}}=1+\mathrm{Km}$

Dimana nilai untuk Km adalah 1 untuk sebuah objek dengan penampang melingkar, jadi nilai $C_{M}$ adalah sebagai berikut

$\mathrm{C}_{\mathrm{M}}=1+1=2$

Gaya inersia dapat dicari dengan persamaan berikut:

Force $_{\text {inertia }}=\mathrm{C}_{\mathrm{M}} * \rho^{*} \mathrm{Vol} * \mathrm{a}$

Force $_{\text {inertia }}=2 * 1,025 * 0,916 * 0,045$

Force $_{\text {inertia }}=0,203$ Ton

d. Gaya Apung

Persamaan yang digunakan untuk menentukan nilai dari gaya apung adalah sebagai berikut:

Force $_{\text {bouyancy }}=$ density $_{\text {seawater }} *$ Volume $_{\text {object }}$ 
Force $_{\text {bouyancy }}=1,025 * 0,916$

e. Gaya Angkat

$$
\text { Force }_{\text {bouyancy }}=0,939 \text { Ton }
$$

Persamaan untuk menghitung gaya angkat dari Reef Ball adalah sebagai berikut:

$$
\begin{array}{ll}
\text { Force }_{\text {lift }}= & C L * \rho * S * \frac{U^{2}}{2} \\
\text { Force }_{\text {lift }}= & 1 * 1,025 * 5,108 * \frac{0,547^{2}}{2} \\
\text { Force }_{\text {lift }}= & 0,783 \text { Ton } \\
\text { Dimana, } & \\
\mathrm{CL} & : \text { Koefesien Angkat }=1 \\
\rho & : \text { Densitas air laut }=1,025 \text { ton } / \mathrm{m}^{3} \\
\mathrm{~S} & : \text { Luas dari perencanaan objek } \\
\mathrm{U} & : \text { Kecepatan maksimum partikel air }
\end{array}
$$

f. Gaya Geser Friksi

Persamaan dasar untuk menghitung gaya geser friksi dengan nilai $\mu$ yang telah di uji sebagai berikut:

$\mu=0.4$ for cocrete sliding on ?ard plastic

$\mu=0.5$ for concrete sliding on submerged sand

Gaya geser friksi dihitung dengan persamaan berikut:

Force $_{\text {resistant }}=\mu$ Weig tobject dry $_{\text {orce }}-$ Fouyancy $_{\text {borce }}$ lift

Force $_{\text {resistant }}=0,52,19-0,939-0,783$

Force $_{\text {resistant }}=0,238$ Ton

g. Faktor Keamanan (FS)

Faktor keamanan perlu dihitung agar Reef Ball dapat bekerja secara maksimal dan mengantisipasi faktor yang tak terduga. Persamaan yang digunakan sebagai berikut:

$$
\begin{aligned}
& \text { Force }_{\text {wave }} * F S=\text { Force }_{\text {resisting }} \\
& F S=\frac{\text { Force }_{\text {resisting }}}{\text { Force }_{\text {wave }}} \\
& F S=\frac{0,238}{0,199} \\
& F S=1,2>10 K ! !
\end{aligned}
$$

Dimana,

$\begin{array}{ll}\mathrm{CL} & : \text { Koefesien Angkat }=1 \\ \rho & : \text { Densitas air laut }=1,025 \\ \mathrm{~S} & : \text { Luas dari perencanaan objek } \\ \mathrm{U} & : \text { Kecepatan maksimum partikel air } \\ \mathrm{CM} & : \text { Koefesien inersia } \\ \mathrm{H} & : \text { Tinggi gelombang } \\ \mathrm{CD} & : \text { Koefesien Geser } \\ \mathrm{CL} & : \text { Luas Penampang } \\ \mathrm{T} & : \text { Periode }\end{array}$

e. Bahan dan Material

Bahan pengisi yang digunakan untuk terumbu buatan tersebut adalah beton. Jenis semen atau bahan pengikat beton yang digunakan pada konstruksi reef balls menggunakan semen pada kategori $V$ atau yang memiliki ketahanan tinggi terhadap kadar sulfat (Murdock, L. J. dan Brook, K. M., 1999). Semen katergori V biasa 
digunakan untuk bangunan pantai dan bangunan yang berhubungan langsung dengan air laut maupun air gambut. Reef balls memerlukan 0,916 m3 beton.

\section{Kesimpulan}

Kesimpulan

Berdasarkan hasil perhitungan dan analisa yang telah dilakukan dapat ditarik beberapa kesimpulan sebagai berikut:

Lokasi penempatan berada pada koordinat N 00 45'33.8”, E 1080 42' 19.5" sampai N 00 $45^{\prime} 29.2^{\prime \prime}$ E 1070 15' 49.0" dengan kedalaman rata-rata 3 meter. Kulitas air pada lokasi perencanaan memenuhi standar baku mutu kehidupan terumbukarang berdasarkan pada PERMEN LH No 51 Tahun 2004. Dimensi untuk ukuran terumbu karang buatan yang digunakan berdasarkan hasil perhitungan $1,80 \mathrm{~m}$, tinggi $1,30 \mathrm{~m}$ dengan tebal lapisan $20 \mathrm{~cm}$ serta lubang yang berada pada sisi-sisi terumbu buatan sebanyak 34 lubang dengan diameter $15 \mathrm{~cm}$. Volume material beton yang digunakan yaitu sebanyak $0,916 \mathrm{~m}^{3}$ atau setara dengan 2,198 ton. Perletakan reef balls dibagi menjadi tiga bagian, panjang tiap bagian adalah 100 meter dengan jarak tiap bagian 25 meter. Jumlah reef balls yang diperlukan tiap bagian adalah 278 tiap bagian, total reef balls yang digunakan adalah 834 buah reef balls. Bahan atau material yang digunakan yaitu semen tipe $V$.

\section{Daftar Pustaka.}

Badan Pusat Statistik, 2012. "Kecamatan Sungai Raya Kepulauan Dalam Angka 2013"

Bengen, D.G, 2002. "Sinopsis Ekosistem Sumber Daya Alam Pesisir dal Laut serta Prinsip Pengelolaannya", Bogor, Pusat Kajian Sumber Daya Pesisir dan Lautan, Institut Pertanian Bogor.

Burke L., Selig E., Spalding M, 2002. "Terumbu Karang yang Terancam di Asia Tenggara (Ringkasan untuk Indonesia)", World Resource Institute, Amerika Serikat.

Dahuri, R., Rais J., Ginting SP., dan Sitepu, 1996. "Pengelolaan Sumberdaya Wilayah Pesisir dan Laut Secara Terpadu". PT. Pradnya Pramita. Jakarta

Departemen Kelautan dan Perikanan, 2004. "Surat Keputusan Ditjen KP3K No. SK.46C/p3K/IX/2004 (Lampiran III), Pedoman Pengelolaan Terumbu Karang, Unit Pelaksana Teknis Rehabilitasi dan Pengelolaan Terumbu Karang", Ditjen., Kp3K.

Dinas Perikanan dan KelautanProvinsi Kalimantan Barat, 2005. "Master Plan Kawasan Konservasi Laut Daerah (Laporan Akhir) Kabupaten Bengkayang (Bku I: Pengelolaan KKLD)", Pontianak.

Direktorat Jendral Kelautan, Pesisir dan Pulau-pulau Kecil, 2005. "Pedoman Pengelolaan Terumbu Buatan dan Transplantasi Karang". Departemen Kelautan dan Perikaan. $93 \mathrm{hlm}$.

Harris L E, 2001. "Stability Analisis for The Submerged Reef Ball Breakwater Proposed or The (Undiclosed Hotel) Resort".

Murdock, L. J. dan Brook, K. M., 1999, "Bahan dan Praktek Beton"; diterjemahkan oleh Ir. Stephanus Hendarko, Jakarta: Erlangga

Simamora, T D, 2012. "Studi Identifikasi Kerusakan Pantai Serta Kelayakan Bangunan Pengaman Pantai di Kabupaten Bengkayang". [Skripsi] Fakultas Teknik. Universitas Tanjungpura.

Westmacott S., Teleki K., Wells S., dan West .,2000. "Pengelolaan Terumbu Karang yang Telah Memutih dan Rusak Kritis", Diterjemahkan oleh Jang Hanning Steffen IUNC, Gland, Switzerland and Cambridge, Inggris Information Press, Oxford. 